\title{
Cervical Ripening With Multiple Medical or Combined Induction Methods: Risks of Subsequent Preterm Birth in Nulliparous Women
}

Naama Farago ( $\square$ naamafrg@gmail.com )

Rambam Medical Center: Rambam Health Care Campus https://orcid.org/0000-0002-1788-6931

\section{Yuval Ginsberg}

Rambam Health Care Campus and Technion- Israel Institute of Technology https://orcid.org/00000002-1651-7501

\section{Gal Bachar}

Rambam Health Care Campus

\section{Ron Beloosesky}

Rambam Health Care Campus and Technion- Israel Institute of Technology

\section{Dana Vitner}

Rambam Health Care Campus and Technion- Israel Institute of Technology

\section{Zeev Weiner}

Rambam Health Care Campus and Technion- Israel Institute of Technology

\section{Nadir Ganem}

Rambam Health Care Campus

Nizar Khatib

Rambam Health Care Campus and Technion- Israel Institute of Technology https://orcid.org/00000002-3069-6630

\section{Research Article}

Keywords: Medical Induction, Double Balloon Catheter, Combined induction, Prenatal Outcome, Preterm birth

Posted Date: May 10th, 2021

DOI: https://doi.org/10.21203/rs.3.rs-460062/v1

License: (c) (i) This work is licensed under a Creative Commons Attribution 4.0 International License. Read Full License 
Version of Record: A version of this preprint was published at International Journal of Gynecology \& Obstetrics on January 22nd, 2022. See the published version at https://doi.org/10.1002/ijgo.14108. 


\section{Abstract}

Objectives: Cervical ripening is one of the most frequently used procedures in modern obstetrics; it can be conducted with mechanical (single or double balloon), medical (PGE2), or combinations of both methods. We aimed to determine the impact of combined methods on the risk of preterm birth in subsequent pregnancy, in nulliparous women.

Methods: A retrospective cohort study of term singleton gestations in nulliparous women, who were induced by mechanical, medical, or combined methods for any indication, managed at one tertiary medical center from 2019 to July 2019, and had their subsequent second birth in our institution. Study groups were compared to a control group of nulliparous women not induced. The primary outcome was risk of preterm labor in the second consecutive birth. Secondary outcomes included maternal and fetal complications, postpartum hemorrhage, chorioamnionitis, mode of delivery, and fetal Apgar score.

Results: Our cohort included 1277 nulliparous women who underwent cervical ripening with mechanical, medical, or combined methods, and a subsequent singleton live birth in our institution. Our study group consisted of 942 women induced by one dose of PGE2, 248 women induced by multiple doses of PGE2 or combined methods, and 87 women induced by mechanical method. The study group was matched to 3903 women in the control group. Demographic data of the four groups were identical, including maternal age, body mass index, and maternal diseases. The rates of spontaneous pre-term birth in the subsequent births, defined as birth at $<37$ weeks, did not differ among the four groups $(4.9 \%$ in single dose group, $2 \%$ in multiple induction group, $6.9 \%$ in mechanical induced group, and $4.3 \%$ in the control group). Moreover, the rates of spontaneous early preterm birth at $<34$ weeks did not differ among the groups.

Conclusions: Cervical ripening with combined methods or multiple medical doses did not increase the rate of subsequent spontaneous preterm births in nulliparous women. The rate of maternal or fetal complications was identical in our study and control group.

\section{Contribution}

What are the novel findings of this work?

The present study addresses impact of combined mechanical and medical induction, or repeated doses of medical induction, and risk of preterm labor in the subsequent pregnancy in primiparous, nulliparous women scheduled for labor induction with multiple prostaglandin doses, or combined medical and mechanical methods.

What are the clinical implications of this work?

Our finding highlights the safety of multiple medical doses or combined medical/mechanical methods in nulliparous women. Physicians should be aware this approach is safe and does not pose maternal or 
neonatal risks.

\section{Introduction}

Induction of labor is a procedure widely used in modern obstetrics, usually performed when continuing the pregnancy poses a risk to fetal or maternal safety. The rate of this procedure has increased worldwide and reached 18 percent in the USA, moreover approximately one-third of women in the UK are induced. ${ }^{1-2}$ Cervical ripening can be carried out by a variety of methods, ${ }^{3-4}$ mainly depending on the Bishop score. Unfavorable cervix is usually induced by drugs or mechanical devices. Prostaglandin drugs, dinoprostone and misoprostol, are the most common preparations used for cervical ripening. In mechanical method, single or double balloon devices are widely used. The proposed mechanism of the double balloon is to apply internal and external pressure on the internal and external cervical OS simultaneously, ${ }^{5-6}$ whereas in single balloon the cervical ripening is achieved by direct expansion of the balloon on the cervix and lower uterine segment. In addition, the balloon catheter enhances prostaglandin secretions, which are probably also engaged in cervical ripening. ${ }^{7}$

Preterm birth is a serious obstetrics burden responsible for a diversity of obstetrics complications, including almost half of congenital neurologic invalidity and the majority of fetal deaths. ${ }^{8-9}$ Cervical weakness, either congenital or following cervical trauma, is a risk factor for cervical insufficiency, which increases the risk of preterm birth. Numerous studies have addressed the impact of mechanical or medical induction on risk of preterm labor in the subsequent pregnancy, but the impact of combined or repeated doses on subsequent pregnancy has not yet been studied. There is a hypothetical risk that the mechanical stretching of the cervix by multiple medical doses or combined induction methods can lead to cervical tissue damage and potentially increase the risk of preterm birth (PTB) in a subsequent pregnancy. In this study we aimed to test whether combined induction methods or multiple doses of prostaglandin could lead to cervical insufficiency, and increase the risk of preterm labor in the subsequent pregnancy.

\section{Materials And Methods}

A case control cohort study of nulliparous pregnant women who delivered in our hospital during 20092019. The local ethics committee approved this study (RMB-0310-19). Our study included the following groups: (1) single round of pharmacological induction, (2) multiple inductions (i.e., two or more rounds of pharmacological induction or both pharmacological and mechanical induction), (3) mechanical induction, and (4) control group (without intervention).

Data was retracted from the hospital's computerized database and included maternal age, diseases, and postpartum parameters as well as neonatal. Data was validated by the authors, all registered MDs, by randomly reviewing the accuracy of data retracted from the written charts. The study group included nulliparous women who underwent induction of labor by mechanical or medical cervical ripening methods, and delivered their subsequent labor in our medical center. Thus was randomly matched by 
computer to a control group that included nulliparous women who did not undergo induction of labor by any type of cervical ripening method, and delivered their subsequent labor in our hospital. Matching ratio was 1:3 in favor of the control group. To minimize the effect of previous pregnancy event on the rate of preterm birth in future pregnancy, only nulliparous pregnant women were included in our study.

Pregnant women scheduled for cervical ripening were included in our study, using prostaglandin or double balloon catheter (Cook Cervical Ripening Ballon, Cook OB/GYN, IN, USA) which was administered according to the manufacture's guideline. Stated amount of $80 \mathrm{cc}$ fluid was placed above and below the cervical OS. Induction of labor was performed based on department protocol; all women with low Bishop scores were induced by prostaglandin or double balloon catheter. At 24 hours following labor induction, pregnant women induced with double balloon without cervical dynamic changes in PV examination were treated with prostaglandin, and the labor induction process was continued by additional doses of prostaglandin or double balloon catheter.

Exclusion criteria included multiple gestation, intra uterine fetal death, third trimester termination of pregnancy, and prenatally diagnosed fetal anomalies not comparable with life. Inclusion criteria included term pregnant women with viable fetus, who had labor induction with cervical ripening either with medical or mechanical method.

Primary outcome was the rate of preterm births in the subsequent labor after induction of labor by cervical ripening method. Secondary outcomes were mode of delivery and maternal complications during first labor, and neonatal outcome (Apgar score and neonatal intensive care unit (NICU) transfer).

\section{Statistical analysis}

Descriptive statistics in terms of mean, SD, median, IQR, and percentages were calculated for all parameters in the study. Normal distribution of the continuous parameters was tested by KolmogorovSmirnov test. The results of this test were used in subsequently conducting ANOVA or Kruskal Wallis test with multiple comparisons made among groups. Differences between categorical parameters were tested by chi square analysis. Linear regression model was conducted to predict gestation age for the next pregnancy using several independent parameters: group, background diseases, and mother's age and $\mathrm{BMI}$, with $\mathrm{P}<0.05$ considered as significant. SPSS, version 27 was used for all statistical analysis.

\section{Results}

The 1,277 women included in the study group were matched with 3,903 women in the control group. The study group included 942 women in the single round of pharmacological induction group, 248 in the multiple attempts induction group (two or more rounds of pharmacological induction and either pharmacological or mechanical induction methods), 87 in the mechanical induction group, and 3,903 in the control group. Demographic data and clinical characteristics comparison among the groups are presented in Table 1. 
Table 1

Demographic data - first labor

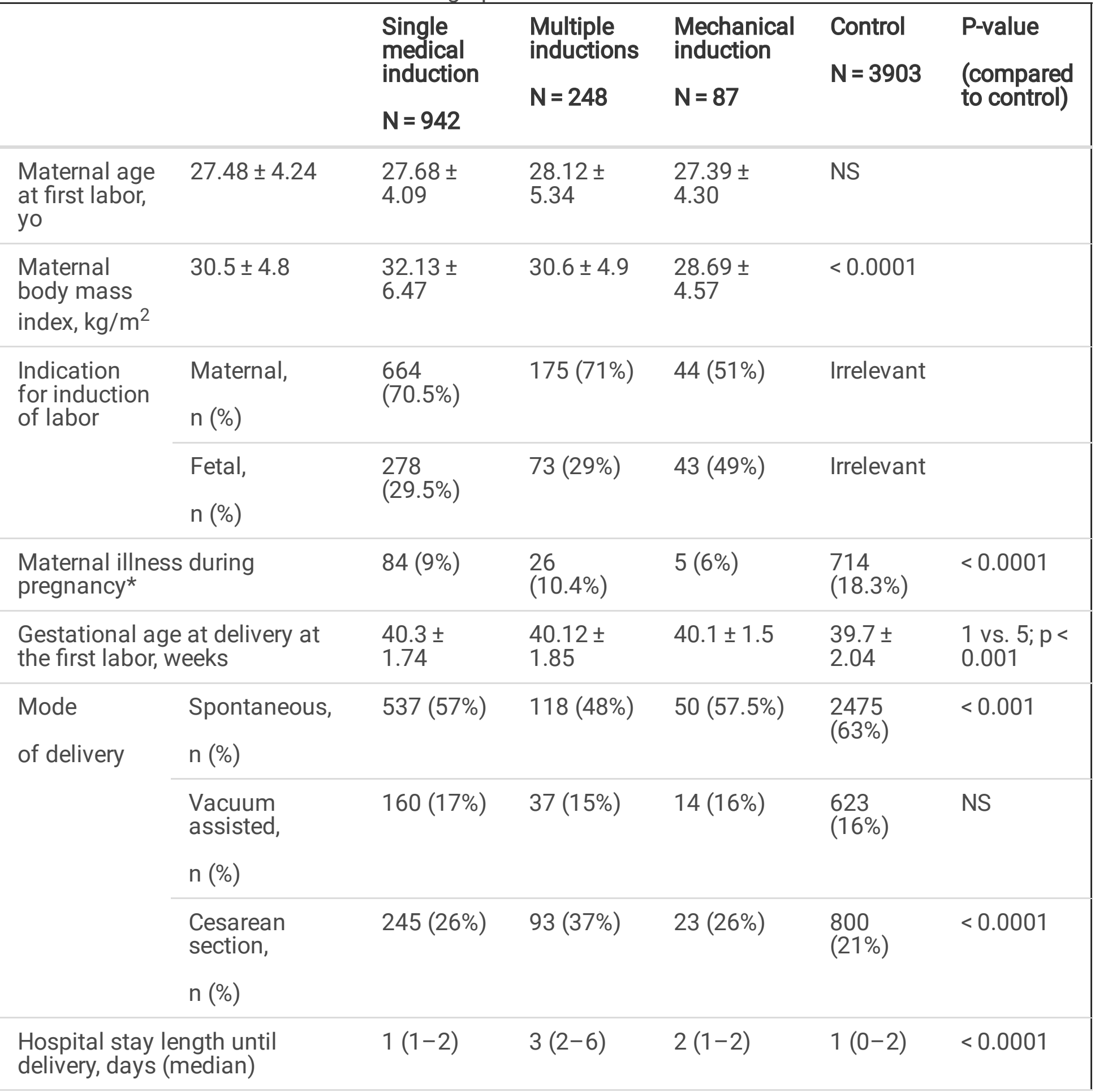

NS, not significant; n, number; NICU, neonatal intensive care unit;

*chronic hypertension, gestational and pregestational diabetes, asthma, and endocrine, renal, neurologic, hematologic and psychiatric disorders.

${ }^{\dagger}$ Retained placenta, postpartum hemorrhage, shoulder dystocia and 3rd and 4th degree perineal tears.

$\mathrm{P}<0.05$ is considered significant. 


\begin{tabular}{|c|c|c|c|c|c|c|}
\hline & & $\begin{array}{l}\text { Single } \\
\text { medical } \\
\text { induction }\end{array}$ & $\begin{array}{l}\text { Multiple } \\
\text { inductions }\end{array}$ & $\begin{array}{l}\text { Mechanical } \\
\text { induction }\end{array}$ & $\begin{array}{l}\text { Control } \\
N=3903\end{array}$ & $\begin{array}{l}\text { P-value } \\
\text { (compared }\end{array}$ \\
\hline & & $N=942$ & $N=248$ & $N=87$ & & 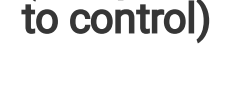 \\
\hline $\begin{array}{l}\text { Maternal, } \\
\text { delivery }^{\dagger} \text {, }\end{array}$ & lications at & $76(8.1 \%)$ & $18(7 \%)$ & $11(12.6 \%)$ & $\begin{array}{l}339 \\
(8.7 \%)\end{array}$ & NS \\
\hline $\begin{array}{l}\text { Fetal } \\
\text { outcome }\end{array}$ & $\begin{array}{l}\text { Apgar score at } \\
1 \text { minute }<7, \mathrm{n} \\
(\%)\end{array}$ & 865 (92\%) & 229 (92\%) & $81(93 \%)$ & $\begin{array}{l}3690 \\
(95 \%)\end{array}$ & 0.006 \\
\hline & $\begin{array}{l}\text { Apgar score at } \\
5 \text { minute }<7, n \\
(\%)\end{array}$ & 932 (99\%) & 245 (99\%) & 86 (99\%) & $\begin{array}{l}3849 \\
(100 \%)\end{array}$ & NS \\
\hline & $\begin{array}{l}\text { NICU transfer, } \\
\text { n (\%) }\end{array}$ & $29(3 \%)$ & $11(4.4 \%)$ & $4(5 \%)$ & $\begin{array}{l}206 \\
(5.3 \%)\end{array}$ & NS \\
\hline $\begin{array}{l}\text { Interpregn } \\
\text { (months) }\end{array}$ & interval & $\begin{array}{l}29.4 \pm \\
13.6\end{array}$ & $\begin{array}{l}30.47 \pm \\
14.56\end{array}$ & $20.7 \pm 6.4$ & $\begin{array}{l}27.9 \pm \\
12.0\end{array}$ & $<0.0001$ \\
\hline NS, not si & t; n, number; & , neonatal & ensive care & & & \\
\hline $\begin{array}{l}{ }^{*} \text { chronic } b \\
\text { neurologi }\end{array}$ & $\begin{array}{l}\text { Ision, gestation } \\
\text { tologic and psy }\end{array}$ & $\begin{array}{l}\text { and preges } \\
\text { atric disor }\end{array}$ & $\begin{array}{l}\text { onal diabe } \\
\text { s. }\end{array}$ & asthma, an & docrine & hal, \\
\hline $\begin{array}{l}{ }^{\dagger} \text { Retainec } \\
\text { tears. }\end{array}$ & ta, postpartun & morrhage, & ulder dys & a and 3rd ar & 4th degre & erineal \\
\hline$P<0.05$ is & dered significar & & & & & \\
\hline
\end{tabular}

There were no significant differences in rates of spontaneous preterm birth in the study groups compared to the control group in the index pregnancy ( $4.9 \%$ in the single dose group, $2 \%$ in the multiple induction group, $6.9 \%$ in mechanical induced group, and $4.3 \%$ in the control group). Moreover, the rates of early preterm births (<34 weeks) did not differ among the groups (Table 2). Multivariate logistic regression was performed to match for variables that may be confounders. Maternal age, BMI, and maternal diseases (hypertension, diabetes) were entered into the model. The rates of subsequent preterm birth remained non-significant. 
Table 2

The relation between type of induction to gestational age at second delivery

\begin{tabular}{|c|c|c|c|c|c|}
\hline & $\begin{array}{l}\begin{array}{l}\text { Single } \\
\text { medical } \\
\text { induction }\end{array} \\
\mathrm{N}=942\end{array}$ & $\begin{array}{l}\begin{array}{l}\text { Multiple } \\
\text { inductions }\end{array} \\
\mathrm{N}=\mathbf{2 4 8}\end{array}$ & $\begin{array}{l}\begin{array}{l}\text { Mechanical } \\
\text { induction }\end{array} \\
\mathrm{N}=87\end{array}$ & $\begin{array}{l}\text { Control } \\
\mathrm{N}= \\
3903\end{array}$ & $\begin{array}{l}\text { P-value } \\
\text { (compared to } \\
\text { control group) }\end{array}$ \\
\hline $\begin{array}{l}\text { Gestational age at } \\
\text { second delivery, weeks }\end{array}$ & $39.8 \pm 2.02$ & $\begin{array}{l}40.03 \pm \\
1.46\end{array}$ & $\begin{array}{l}39.55 \pm \\
2.40\end{array}$ & $\begin{array}{l}39.83 \\
\pm 1.87\end{array}$ & NS \\
\hline $\begin{array}{l}\text { Delivery bellow } 34 \text { weeks, } \\
\text { n(\%) }\end{array}$ & $15(1.6 \%)$ & 0 & $2(2.3 \%)$ & $\begin{array}{l}48 \\
(1.2 \%)\end{array}$ & NS \\
\hline $\begin{array}{l}\text { Delivery between } 34+1 \text { to } \\
36+6 \text { weeks, } n(\%)\end{array}$ & $27(2.9 \%)$ & $6(2.5 \%)$ & $4(4.6 \%)$ & $\begin{array}{l}119 \\
(3.1 \%)\end{array}$ & NS \\
\hline $\begin{array}{l}\text { Delivery after } 37 \text { weeks, } \\
\mathrm{n}(\%)\end{array}$ & 897 (95.5\%) & 242 (98\%) & $81(93.1 \%)$ & $\begin{array}{l}3725 \\
(95.7 \%)\end{array}$ & NS \\
\hline
\end{tabular}

The control group had the highest rate of vaginal delivery at first birth as compared to the study groups: single round of pharmacological induction group, induction group, and mechanical induction group (63\% vs. $57 \%, 48 \%$, and $57.5 \%$, respectively, $P$ value $<0.0001$ ). The rate of cesarean deliveries in the first pregnancy in the multiple induction group was significantly higher as compared with the control group $(37 \%$ vs. $21 \%, p<0.0001)$.

We did not find any significant differences in secondary outcomes, including maternal complications and neonatal outcomes.

\section{Discussion}

In this retrospective study we tested the impact of repeated medical or combined methods of labor induction, and risk of preterm labor in subsequent pregnancy in nulliparous women. Our data indicating that repeated attempts, either medical or combined methods, did not increase the rates of preterm labor in subsequent pregnancy.

Cervical trauma presents an important reason for cervical incompetence, leading to premature delivery. Numerous studies reported comparable results, concluding that mechanical or medical induction of labor $^{10-13}$ does not increase the risk of premature labor in subsequent pregnancy. Although, these studies addressed the same research question, no data was available to answer the question whether repeated attempts, or combined methods of labor induction, in nulliparous women increase the risk of PTB in a subsequent pregnancy. Furthermore, heterogeneity exists between these studies in term of parity, type of catheter, amount of fluids placed on the catheter, and whether or not traction was applied. It is feasible to postulate that combined methods or repeated medical labor induction have a traumatizing impact on the 
cervical integrity, preventing the cervix from functioning adequately in future pregnancies, which could lead to spontaneous PTB; such an assumption was not tested before.

Zafran et al. ${ }^{11}$ pointed out several differences in studies reporting that induction of labor did not increase the rate of premature birth in subsequent pregnancy; among these variations the amount of the fluids placed in the catheter and type of catheter placed in the cervix. Thus too strengthen our study; we included only nulliparous women and double-balloon catheter. In accordance with reports claiming that the amount of fluids inflated into single-balloon catheter plays an important role in the success of cervical ripening, ${ }^{13-15}$ we placed a high but set amount of $80 \mathrm{cc}$ fluids above and below the internal OS. consideration factors which increase the cervical weakness, it is rational to assume that repeated medical induction attempts or combined methods (medical and mechanical) where a high amount of fluids is placed in the balloon above and below the internal OS, could potentially lead to more cervical tissue injury and therefore have a negative effect on cervical perfection. Our data did not validate this assumption, this approach is safe and did not increase the rate of premature labor in nulliparous in subsequent pregnancy compared to the control group.

Almost 250 nulliparous women were treated with multiple doses of prostaglandin or combined medical and mechanical methods, with no cases of premature labor before 34 weeks observed in this group. The rate of late premature birth between 34-36.6 gestational weeks was $3.1 \%$ in the control group, compared to $2.9 \%, 1.5 \%, 6.1 \% 4.6 \%$, respectively, in single medical induction, multiple doses, combined mechanical and medical, and mechanical and mechanical induction groups, respectively. Looking at the group induced by prostaglandin and double-balloon catheter, and the double-balloon induction group, we observed a slightly increased rate of premature labor between 34-36.6 gestational weeks compared to the other groups (Table 2). We assume that this difference could be attributed in part to the shorter pregnancy interval observed in these two groups (Table 1). Previous studies have found that short intervals between the birth of one child and next pregnancy are associated with an increased risk of preterm birth [16-18]; nevertheless, this slight increase was not statistically significant. Moreover, the fetal secondary outcomes in term of admission to NICU or fetal Apgar score were similar in all groups

In this study, the mechanical group was induced only by double-balloon catheter. In spite of the high amount of fluids placed on the catheter and the traction act, comparable with other studies, we did not observe a significant increased rate of preterm birth. The similarity in preterm birth in all groups, regardless of the induction method, favors the hypothesis that the main mechanism of cervical ripening by the double balloon could be related to prostaglandin release from decidual separation as in single balloon catheters ${ }^{7}$, rather than by its mechanical effects.

Cesarean delivery was significantly higher in the multiple induction group compared to the control (Table 1). This difference can be attributed to the following: first, we assume that in the combined induction group women were exhausted, as the induction process extended to several days compared to the other groups ( 3 days compared to 2 days in the mechanical group, one day in the single dose and control group, Table 1). We believe that the women exhaustion played an important role in the decision of 
delivery mode. Furthermore, this group included high-risk pregnant women who underwent labor induction, which can raise the risk of cesarean section and instrumental delivery.

Although this study has the limitation of being retrospective, it has several strengths. It is the first study testing the hypothesis that pregnant women induced with multiple doses of prostaglandin or with combined methods could have a negative impact on cervical competency, which could lead to premature labor on subsequent pregnancy. This is a large cohort study, using data from one medical center, thus minimizing practice variations in labor induction and delivery protocols. Moreover, we included only nulliparous women to minimize differences among groups.

We conclude that nulliparous women, scheduled for labor induction with multiple prostaglandin doses or combined medical and mechanical methods, do not have increased risk of preterm labor in their subsequent pregnancy.

\section{Declarations}

\section{Ethical approval}

This study was done as per the ethical standards set by the Ethical Committee for the human studies, following the 1964 Declaration of Helsinki. The study was approved by the Ethics Committee for human study -Rambam Medical Center (Approval number: 0310-19-RMB. DATED 03.06.2019).

\section{Author contributions}

All authors contributed to the study conception and design. Material preparation, data collection and analysis were performed by Naama Farago and Nizar Khatib. The first draft of the manuscript was written by Nizar Khatib and Yuval Ginsberg and all authors commented on previous versions of the manuscript. All authors read and approved the final manuscript.

\section{Funding}

no external funding was used in writing this article.

\section{Conflicts of interest/Competing interests}

The authors have no conflicts of interest to declare

\section{Availability of data and material}

raw anonymous data will be available on demand.

\section{Code availability}

Not applicable 


\section{References}

1. Hamilton BE, Martin JA, Osterman MJK, Curtin SC, Mathews TJ. Births: Final data for 2014. National vital statistics reports 2015; 64(12). National Vital Statistics System, National Center for Health Statistics, Centers for Disease Control and Prevention, https://stacks.cdc.gov/view/cdc/36961. [24 February 2021].

2. NHS Digital. NHS Maternity Statistics 2016-2017. https://files.digital.nhs.uk/pdf/l/1/hosp-epis-statmat-repo-2016-17.pdf. [24 February 2021].

3. Boulvain M, Kelly A, Lohse C, Stan C, Irion O. Mechanical methods for induction of labour. Cochrane Database Syst Rev. 2001; (4) : CD001233. doi: 10.1002/14651858.CD001233.

4. Gelber S, Sciscione A. Mechanical methods of cervical ripening and labor induction. Clin Obstet Gynecol 2006; 49 : 642-57.

5. Atad J, Hallak M, Ben-David Y, Auslender R, Abramovici H. Ripening and dilatation of the unfavourable cervix for induction of labour by a double balloon device: experience with 250 cases. $\mathrm{Br}$ J Obstet Gynaecol.1997; 104 : 29-32.

6. Salim R, Zafran N, Nachum Z, Garmi G, Kraiem N, Shalev E. Single-balloon compared with doubleballoon catheters for induction of labor: a randomized controlled trial. Obstet Gynecol2011; 118: 7986.

7. Manabe Y, Manabe A, Takahashi A. F prostaglandin levels in amniotic fluid during balloon-induced cervical softening and labor at term. Prostaglandins 1982; 23 : 247-56.

8. Goldenberg RL, Culhane JF, lams JD, Romero R. Epidemiology and causes of preterm birth. Lancet 2008; 371 : 75-84.

9. McCormick MC. The contribution of low birth weight to infant mortality and childhood morbidity. $N$ Engl J Med 1985; 312: 82-90.

10. Sciscione A, Larkin M, O'Shea A, Pollock M, Hoffman M, Colmorgen G. Preinduction cervical ripening with the Foley catheter and the risk of subsequent preterm birth. Am J Obstet Gynecol 2004; 190 : 751-4.

11. Zafran N, Garmi G, Zuarez-Easton S, Nachum Z, Salim R. Cervical ripening with the balloon catheter and the risk of subsequent preterm birth. $J$ Perinatol 2015; 35 : 799-802.

12. de Vaan MDT, Blel D, Bloemenkamp KWM, Jozwiak M, Ten Eikelder MLG, de Leeuw JW, Oudijk MA, Bakker JJH, Rijnders RJP, Papatsonis DN, Woiski M, Mol BW, de Heus R. Induction of labor with a Foley catheter and the risk of subsequent preterm birth: A follow-up study of two randomized controlled trials (PROBAAT-1 and -2). Ultrasound Obstet Gynecol 2020; 57 : 292-297.

13. Delaney S, Shaffer BL, Cheng YW, Vargas J, Sparks TN, Paul K, Caughey AB. Labor induction with a Foley balloon inflated to $30 \mathrm{~mL}$ compared with $60 \mathrm{~mL}$ : a randomized controlled trial. Obstet Gynecol 2010; 115 : 1239-45.

14. Levy R, Kanengiser B, Furman B, Ben Arie A, Brown D, Hagay ZJ. A randomized trial comparing a 30$\mathrm{mL}$ and an 80-mL Foley catheter balloon for preinduction cervical ripening. Am J Obstet Gynecol 
2004; 191 : 1632-6.

15. Kashanian M, Nazemi M, Malakzadegan A. Comparison of 30-mL and 80-mL Foley catheter balloons and oxytocin for preinduction cervical ripening. Int J Gynaecol Obstet 2009; 105 : 174-5.

16. Klerman LV, Cliver SP, Goldenberg RL. The impact of short interpregnancy intervals on pregnancy outcomes in a low-income population. Am J Public Health 1998; 88 : 1182-5.

17. Shults RA, Arndt V, Olshan AF, Martin CF, Royce RA. Effects of short interpregnancy intervals on small-for-gestational age and preterm births. Epidemiology 1999; 10 : 250-4.

18. Manabe Y, Manabe A, Takahashi A. F prostaglandin levels in amniotic fluid during balloon-induced cervical softening and labor at term. Prostaglandins 1982; $23: 247-56$. 